\title{
A Multi-Center Retrospective Comparison of Induction Chemoimmunotherapy Regimens on Outcomes in Transplant-eligible Patients with Previously Untreated Mantle Cell Lymphoma
}

$\underline{\text { Zi Yun } \mathrm{Ng}^{1}, \text { Mark Bishton }^{2} \text {, David Ritchie }}{ }^{3}$, Robert Campbell ${ }^{4}$, Michael Gilbertson $^{5}$, Kate Hill $^{6}$, Sumita Ratnasingam ${ }^{5}$, Anthony Schwarer ${ }^{7}$, Kate Manos $^{8}$, Sophie Shorten ${ }^{9}$, Melissa Ng ${ }^{10}$, Niles Nelson $^{11}$, Liu Xin ${ }^{12}$, Sanjay De Mel Widanalage ${ }^{12}$, Tenny Sunny ${ }^{13}$, Duncan Purtill ${ }^{13}$, Michelle Poon ${ }^{12}$, Anna Johnston $^{11}$, Tara Cochrane ${ }^{10}$, Hui-Peng Lee ${ }^{8}$, Greg Hapgood ${ }^{6}$, Constantine Tam ${ }^{3,9}$, Stephen Opat $^{5}$, Eliza Hawkes ${ }^{4,7}$, John Seymour ${ }^{3}$, Chan Yoon Cheah ${ }^{1,14}$.

${ }^{1}$ Department of Haematology, Sir Charles Gairdner Hospital, Nedlands, Western Australia, Australia ${ }^{2}$ Department of Haematology, Nottingham University Hospitals NHS Trust, Nottingham, United Kingdom

${ }^{3}$ Department of Haematology, Royal Melbourne Hospital \& Peter MacCallum Cancer Centre, and University of Melbourne, Melbourne, Victoria, Australia

${ }^{4}$ Department of Medical Oncology and Clinical Haematology, Olivia Newton John Cancer Research and Wellness Centre, Austin Health, Heidelberg, Victoria, Australia

${ }^{5}$ Clinical Haematology, Monash Health and Monash University, Clayton, Victoria, Australia

${ }^{6}$ Cancer Care Services, Princess Alexandra Hospital, Brisbane, Queensland, Australia

${ }^{7}$ Department of Medical Oncology, Eastern Health, Box Hill, Victoria, Australia

${ }^{8}$ Department of Haematology, Flinders Medical Centre, Bedford Park, South Australia, Australia

${ }^{9}$ Department of Haematology, St Vincent's Hospital, Fitzroy, Victoria, Australia

${ }^{10}$ Department of Haematology, Gold Coast University Hospital, Southport, Queensland, Australia

${ }^{11}$ Department of Haematology, Royal Hobart Hospital, Hobart, Tasmania, Australia

This is the author manuscript accepted for publication and has undergone full peer review but has not been through the copyediting, typesetting, pagination and proofreading process, which may lead to differences between this version and the Version of Record. Please cite this article as doi: 10.1002/hon.2618

This article is protected by copyright. All rights reserved. 
${ }^{12}$ Department of Haematology-Oncology, National University Cancer Institute Singapore, National University Health System, Singapore

${ }^{13}$ Department of Haematology, Fiona Stanley Hospital, Murdoch, Western Australia, Australia

${ }^{14}$ Medical School, University of Western Australia, Crawley, Western Australia, Australia

Correspondence: Dr Chan Yoon Cheah, Department of Haematology, Sir Charles Gairdner Hospital, Ground Floor, B Block, Hospital Avenue, Nedlands, WA 6009, Australia; e-mail: chan.cheah@health.wa.gov.au.

\section{Keywords: Mantle Cell Lymphoma, Induction, Conditioning, Autologous Stem Cell Transplant}

Running title: Induction Chemoimmunotherapy in Young MCL Patients

Word count: 2217 words (main manuscript only without abstract)

\section{$\underline{\text { Abstract }}$}

Mantle cell lymphoma (MCL) is an uncommon and typically aggressive form of lymphoma. Although often initially chemosensitive, relapse is common. Several induction and conditioning regimens are used in transplant eligible patients and the optimal approach remains unknown.

We performed an international, retrospective study of transplant eligible patients to assess impact of induction chemo-immunotherapy and conditioning regimens on clinical outcomes.

We identified 228 patients meeting inclusion criteria. Baseline characteristics were similar among the induction groups except for some variation in age. The type of induction chemo-immunotherapy received did not influence overall response rates $(\mathrm{ORR})(P=0.43)$, progression free survival (PFS) 
$(P>0.67)$ or overall survival (OS) $(P>0.35)$ on multivariate analysis (PFS and OS). Delivery of ASCT was associated with favourable PFS and OS $(P=0.01)$ on univariate analysis only; this benefit was not seen on multivariate analysis - PFS $(P=0.36)$ and OS $(P=0.21)$. Compared with BuMel (busulfan and melphalan), the use of the BEAM (carmustine, etoposide, cytarabine, melphalan) conditioning regimen was associated with inferior PFS (HR=2.0 [95\%CI 1.1-3.6], $P=0.02)$ but not $\mathrm{OS}(\mathrm{HR}=1.1$ [95\%CI 0.5-2.3] $P=0.81$ ) on univariate analysis only.

Within the limits of a retrospective study and modest power for some comparisons, type of induction therapy did not influence ORR, PFS or OS for transplant eligible patients with MCL. International efforts are required to perform randomized clinical trials evaluating chemo-immunotherapy induction regimens.

\section{$\underline{\text { Introduction }}$}

Mantle cell lymphoma (MCL) is an uncommon subtype of non-Hodgkin lymphoma, with an increasing annual incidence of 0.8 per 100,000 population in Western countries. ${ }^{1}$ The median age at diagnosis is 67 years and there is a strong male predominance. ${ }^{1}$ MCL typically has an aggressive presentation and though often initially chemosensitive, is characterized by inevitable relapse. ${ }^{2}$

In the last decade, the most durable remissions among patients with MCL have followed high dose cytarabine-containing induction and autologous stem-cell transplant (ASCT) in younger patients. ${ }^{3-5}$ However, many pivotal studies were single arm phase II studies and many of the most widely employed regimens have not been directly compared in randomized studies. Thus, the optimal induction and conditioning regimens remain a matter of debate. Common induction regimens 
include the Nordic MCL2 regimen (rituximab (R), cyclophosphamide, vincristine, doxorubicin, prednisone [R-maxi-CHOP]) alternating with high-dose cytarabine $^{6}$ and R-HyperCVAD/MA (hyperfractionated cyclophosphamide, vincristine, doxorubicin and dexamethasone alternating with high dose methotrexate/cytarabine). ${ }^{7}$ Other approaches studied in recent years include R-CHOP alternating with DHAP (dexamethasone, high dose cytarabine and a platinum derivative) ${ }^{4}$ or four cycles of R-DHAP. ${ }^{8}$

The aim of this study was to compare the efficacy of different induction and conditioning regimens in transplant-eligible patients with MCL on clinical outcomes.

\section{Patients and Methods}

\section{Patient Identification}

We performed a multicentre retrospective analysis of newly diagnosed, consecutive patients with MCL treated with induction chemo-immunotherapy and deemed fit for ASCT between December 2001 and December 2015. Patients were excluded if they did not receive rituximab with induction chemotherapy. Patients were included on an intention to treat basis if they were treated with the intensive regimen of choice and considered potentially suitable for ASCT at time of initial diagnosis by the treating physician. This was regardless of whether an ASCT was subsequently performed as certain intensive regimens like R-HyperCVAD/MA were not routinely consolidated with an ASCT.

Patients were identified through review of clinical and pathology databases. Only cases positive for cyclin D1 by immunohistochemistry (IHC) and/or translocation $(11 ; 14)$ by fluorescence in situ hybridisation were included. Ann Arbor stage was determined by bone marrow biopsies and imaging 
with contrast-enhanced computed tomography (CT) scans of chest, abdomen and pelvis and/or ${ }^{18} \mathrm{~F}$ fluorodeoxyglucose positron emission tomography (FDG-PET) scans. Gastrointestinal endoscopies were not routinely performed.

\section{Statistical Methods}

Baseline patient and disease characteristics were compared between treatment groups using the Kruskal Wallis test or Chi-squared test, as appropriate. Responses were defined according to the Lugano 2014 classification ${ }^{9}$ or Cheson 1999 criteria ${ }^{10}$ depending on the time of diagnosis. Progression free survival (PFS) and overall survival (OS) were calculated from date of diagnosis to date of disease progression or death from any cause, or death from any cause, respectively. Patients alive at last observation were censored. Survival curves were estimated using the Kaplan-Meier method and compared using the log-rank test. Univariate Cox regression was used to identify associations between prognostic factors and outcomes, and covariates with P-values $<0.1$ were included in multivariate regression (forward selection). All statistical analyses were carried out using the STATA 14.0 software program for Windows (StataCorp, Texas, US). Data collection was compliant with human research ethics committee or institutional review board requirements at each site.

\section{$\underline{\text { Results }}$}

\section{Patient Characteristics}

228 patients met inclusion criteria and were grouped according to the induction regimen. The five treatment groups were: (1) Nordic MCL2, (2) R-HyperCVAD/MA, (3) R-CHOP, (4) RCHOP/DHAC (cisplatin replaced with carboplatin) and (5) Other. Patients included in the final group 
typically had various combinations of R-CHOP with HyperCVAD, R-CHOP with ESHAP (etoposide, methylprednisolone, cytarabine, cisplatin), R-CHOP with IVE (ifosfamide, epirubicin, etoposide), RCVP (rituximab, cyclophosphamide, vincristine, prednisolone) or R-CEOP (rituximab, cyclophosphamide, etoposide, vincristine, prednisolone).

\section{Baseline Characteristics}

The baseline characteristics of the patients are detailed in Table 1; patients who underwent Nordiclike and Hyper-CVAD regimens had a younger median age than the other groups. After a median follow-up of 4.2 years (range 0.4-15), the 4-year PFS was 62\% (95\%CI 54-69\%) and OS was $84 \%$ (95\%CI 78-88\%) for the entire cohort. By univariate analysis, c-MIPI (combined MCL International Prognostic Index biologic index, with MIPI only if Ki67 was not available) high risk, B symptoms, advanced Ann Arbor stage and bone marrow involvement at diagnosis were adversely prognostic for PFS while c-MIPI, blastoid histology, and B symptoms were adversely prognostic for OS (Table 2). In the multivariate analysis, c-MIPI high-risk group were both adversely prognostic for PFS (HR=2.0 [95\%CI 1.0-3.9], $P=0.04)$ and $\mathrm{OS}(\mathrm{HR}=2.7$ [95\%CI 1.2-6.1], $P=0.03)$. The PFS and OS according to C-MIPI are displayed in Figure 1. A detailed univariate and multivariate analysis of baseline prognostic factors is displayed further in Table 2. Variables that are already accounted for in the cMIPI were not repeated in the uni/multivariate analysis.

\section{Treatment Characteristics}

Treatment received and the outcomes of the patients in the five groups are summarized in Table 3 . More than $70 \%$ of patients in each group underwent myeloablative therapy. Most of the patients in the Nordic MCL2, R-CHOP and 'other' group received BEAM (carmustine, etoposide, cytarabine, 
melphalan) conditioning, while majority of patients in the R-HyperCVAD group received BuMel conditioning. The proportion of patients who received maintenance rituximab was $21 \%$; with 29 out of 47 patients receiving it after myeloablative therapy while 18 patients receiving it after induction therapy only.

\section{Transplant Eligible Patients whom did not undergo ASCT in First Remission}

Fifty-five patients (24\%) did not undergo ASCT in first remission; six (11\%) due to toxicity from induction, three (5\%) due to failure of stem-cell harvesting, 35 (64\%) due to lack of intent for ASCT in first remission although deemed transplant eligible, two (4\%) due to death (one due to invasive aspergillosis and one due to progressive disease), five (9\%) due to other reasons (three due to progressive disease prior to ASCT, one due to patient preference and one due to patient nonadherence to follow-up) and for four patients (7\%), the reason was not documented. Among the 35 patients who did not undergo an ASCT in first remission (although deemed eligible for transplant based on age and organ function criteria), 9 out of 19 patients who experienced disease relapse went on to have an ASCT after $2^{\text {nd }}$ line treatment.

\section{Treatment Outcomes:}

ORR to induction treatment was high $(87-100 \%)$ with a CR rate between $60-88 \%$ in 220 evaluable patients with no significant difference between regimens $(P=0.43)$. Choice of induction regimen was not associated with improvement in PFS (Fig 2A) $(P>0.46)$ or OS (Fig 2B) $(P>0.43)$ by univariate analysis. Multivariate analysis revealed similar findings; type of induction regimen did not affect PFS $(P>0.67)$ or $\mathrm{OS}(P>0.35)$.

\section{Impact of Cytarabine as part of Induction}


When induction regimens were grouped according to the incorporation of cytarabine and the multivariate analysis re-performed, the inclusion of cytarabine was not associated with improvement in PFS (HR=0.8 [95\%CI 0.5-1.5], $P=0.53)$ or OS (HR=1.4 [95\%CI 0.7-2.8], $P=0.34)$.

\section{Impact of Myeloablative Therapy}

Restricting the analysis to only those patients who received an ASCT in first disease response, induction therapy did not influence PFS or OS ( $P=0.69$ and 0.62 respectively, data not shown). To account for potential guarantee-time bias associated with the time necessary to proceed to transplant after induction, among patients with disease responsive to induction therapy that did not experience disease progression within six months of diagnosis $(\mathrm{N}=219)$, actual delivery of ASCT was associated with superior PFS $(P=0.01)$ (Fig 2C) and OS $(P=0.01)$ by univariate analysis. However, the benefit of ASCT was not seen in these patients on multivariate analysis for both PFS $(P=0.36)$ and OS $(P=0.21)$.

\section{Impact of Conditioning Regimen and Maintenance Rituximab}

Relative to BuMel (busulfan and melphalan), the use of BEAM conditioning was associated with inferior PFS $(\mathrm{HR}=2.0$ [95\%CI 1.1-3.6], $P=0.02)$ (Fig 2D) but not OS (HR=1.1 [95\%CI 0.5-2.3] $P=0.81$ ). However, the putative benefit in PFS with BuMel versus BEAM conditioning was not retained on multivariate analysis $(\mathrm{HR}=1.27$ [95\% CI $0.3-5.7] P=0.75)$. This is potentially confounded by the fact that the median age of patients who underwent BuMel conditioning was younger (median age 54, range 29-69 years) compared to patients who underwent BEAM conditioning (median age 58, range 30-73 years). Among the 47 patients (21\%) who received maintenance rituximab posttransplant, there was no association with PFS $(P=0.96)$ or OS $(P=0.47)$. 


\section{$\underline{\text { Discussion }}$}

There are few randomized trials comparing the relative efficacy of current induction regimens in transplant eligible patients with MCL. Within the limits of a retrospective study design, we were unable to detect differences in PFS or OS for the induction regimens studied. Nordic MCL2 and RHyperCVAD/MA are widely used induction regimens, though they are more toxic than BR (bendamustine, rituximab) or R-CHOP. The 15-year update of the original R-HyperCVAD/MA phase II study (median follow-up 13.4 years) showed median overall and failure free survivals of 10.7 years and 4.8 years, respectively. However, $6.2 \%$ of patients (all of whom were in first remission) developed a secondary myeloid malignancy. ${ }^{11}$ The Nordic group also published their 15 year update of the MCL2 trial (median follow-up 11.4 years) with median overall and progression free survivals of 12.7 and 8.5 years, respectively. However, patients with low or intermediate risk MIPI showed a continued pattern of late disease relapses. In contrast to patients treated with the R-HyperCVAD/MA regimen, five patients $(3.1 \%)$ in the Nordic MCL2 cohort developed a secondary myeloid malignancy; however in four of these patients, this occurred in the setting of multiply treated relapsed MCL and therefore higher cumulative chemotherapy exposure. ${ }^{6}$ It should also be noted that more inpatient requirements are needed for higher-dose cytarabine containing regimens like the RHyperCVAD/MA and Nordic MCL2 regimens.

The superiority of alternating R-DHAP with R-CHOP over R-CHOP alone in induction was demonstrated in the MCL Younger study; the time to treatment failure was significantly longer in the cytarabine group (9.1 years) compared to the R-CHOP alone group (3.9 years), although there was no difference in OS. ${ }^{4}$ These data suggest an important role for cytarabine in induction. We were unable 
to confirm the benefit of high-dose cytarabine reported by Hermine et $\mathrm{l}^{4}$ in the 466 patients in the MCL Younger study. Potential reasons for this include our smaller cohort size, retrospective nature of the study and the heterogeneous induction regimens applied. Similarly, the proportion of patients who underwent maintenance rituximab was small as this treatment is not funded in Australia where majority of the patients were treated, therefore its effect was unable to be studied meaningfully.

In the R-HyperCVAD/MA regimen as originally published, ASCT is reserved for the small minority of patients with $<\mathrm{CR}$ after 6 cycles. $^{7}$ Indeed, the R-HyperCVAD/MA regimen may compromise successful stem-cell mobilization ${ }^{3}$, but this can be mitigated by early harvesting. ${ }^{12}$ A smaller study investigating R-HyperCVAD induction followed by a BuMel conditioned ASCT for 12 (out of 13) patients showed this strategy to be feasible with an encouraging 3 year overall and event-free survival of $92 \% .^{13}$ The Nordic MCL2 and R-CHOP/R-DHAP regimens are routinely consolidated with $\mathrm{ASCT}^{4,6}$

Although not the primary endpoint of the study, among patients who responded to induction and did not experience disease progression within six months of diagnosis we did not observe a benefit among those patients who received ASCT as initially planned on multivariate analysis with a PFS $(P=0.36)$ and $\mathrm{OS}(P=0.21)$. The last RCT to show the benefit of consolidation with ASCT compared to interferon maintenance for MCL patients treated with CHOP-like induction was published in 2005 with $<30 \%$ of patients receiving rituximab as part of induction. More recently, Gerson et al ${ }^{14}$ analyzed 1029 patients who survived $>6$ months and achieved at least a partial response and compared the outcomes between those who received an ASCT (64\%) versus those who did not. These series have suggested a benefit to ASCT in the rituximab era. ${ }^{14,15}$ 
It has been debated whether an ASCT is still needed with current more intensive chemoimmunotherapy regimens and/or incorporation of novel agents. Whether the incorporation of highly active agents such as the Btk inhibitor ibrutinib into induction \pm maintenance may replace ASCT is being explored in the ongoing European MCL Network Triangle study (NCT02858258). Transplant eligible patients with MCL are randomized to one of 3 arms: R-CHOP/R-DHAP followed by ASCT, R-CHOP+ibrutinib/R-DHAP followed by ASCT and ibrutinib maintenance, and RCHOP+ibrutinib/R-DHAP followed by ibrutinib maintenance.

Studies addressing the optimal conditioning regimen in patients with MCL are scarce. A prospective study by Chen et al ${ }^{15}$ suggested that using either TBI (total body irradiation) or low dose CBV (cyclophosphamide, carmustine and etoposide) was superior compared to BEAM conditioning for PFS, but this did not translate into an OS benefit. We found use of the BuMel regimen to be associated with superior PFS relative to BEAM (univariate analysis only), however there is also the potential for selection bias as patients in the BuMel cohort were younger and mostly received HyperCVAD induction at a single site. The skewed data distribution also likely compounds the validity of the multivariate analysis performed.

This study has the usual limitations inherent to retrospective study design. Although we attempted to correct for known sources of bias using multivariate analysis, clear imbalances in baseline characteristics likely influenced physician selection of chemotherapy regimen. As the treatments applied were heterogenous, the number of patients in each group was relatively small, limiting statistical power to detect small effect sizes.

\section{Conclusion:}

This article is protected by copyright. All rights reserved. 
Within the limits of a retrospective study and modest power for some comparisons, type of induction therapy did not influence ORR, PFS or OS for transplant eligible patients with MCL. International efforts are required to perform randomized clinical trials evaluating chemo-immunotherapy induction regimens.

\section{$\underline{\text { Additional Information }}$}

Ethics approval and consent to participate:

- This study (HREC No: 2016-067) was approved by Sir Charles Gairdner Group (SCGG) Human Research Ethics Committee (HREC). A waiver of consent was granted for this study.

- This study was performed in accordance with the Declaration of Helsinki.

Consent for publication

- This study does not contain individual person's data.

\section{Conflict of interest}

- Mark Bishton: Takeda - Travel; Abbvie, Roche, Gilead - research grant; Ad board - Janssen

- Duncan Purtill: Amgen, Novartis, Gilead - Travel; Honoraria: Gilead, MSD, Novartis Honoraria; Novartis - Ad Board.

- Anna Johnston: Scientific advisory boards - Roche, Janssen, MSD; Travel - Roche; Honoraria- Janssen

- Tara Cochrane: Takeda, Celgene, BMS, Amgen - Honararia; Janssen, Novartis - Advisory board; Takeda, MSD - Speakers Bureau.

- Eliza Hawkes: Research funding to my institution - Bristol-Myers Squibb, Merck Serono, Celgene, Merck Sharpe Dohme, Astra Zeneca. Advisory Boards - Janssen, Celgene, Merck 
Sharpe Dohme, Roche

Honoraria/Speaker fees - Roche, Janssen, Takeda, Bristol-Myers Squibb. Travel expenses Takeda, Roche, Janssen

- John Seymour: Abbvie - Advisory Board, Speakers' Bureau, Honoraria, research support; Acerta - Advisory Board; Celgene - Advisory Board, Speakers' Bureau, Honoraria, research support; Genentech - Advisory Board, Honoraria, research support; Janssen - Advisory Board, Honoraria, research support; Morphosys - Advisory Board; Roche - Advisory Board, Speakers' Bureau, Honoraria, research support; Takeda - Advisory Board

- Chan Cheah: research grant - Celgene, Roche, Abbvie, Gilead; honoraria (donated) - Janssen, Bristol Myers Squibb, Takeda, Roche, MSD; speaker's beaureau - Gilead, Janssen, Roche, Takeda, MSD; scientific advisory boards - Bristol Myers Squibb, Janssen, Gilead, Takeda, Roche, MSD; travel - Bristol Myers Squibb, Amgen, Roche

- All remaining authors have declared no conflicts of interest.

\section{Funding}

- The authors received no specific funding for this work.

\section{Authors' contributions}

- ZYN and CYC designed the paper, collected, collated and analyzed the data and wrote the manuscript. The remaining authors collected data, critically reviewed and approved the final manuscript. 
Acknowledgements

- $\quad$ ZYN would like to acknowledge the guidance and mentorship of CYC.

\section{References:}

1. Epperla N, Hamadani M, Fenske TS, Costa LJ. Incidence and survival trends in mantle cell lymphoma. Br J Haematol. 2018;181(5):703-706.

2. Swerdlow SH, Campo E, Pileri SA, et al. The 2016 revision of the World Health Organization classification of lymphoid neoplasms. Blood. 2016;127(20):2375-2390.

3. Cheah CY, Seymour JF, Wang ML. Mantle Cell Lymphoma. J Clin Oncol. 2016.

4. Hermine $\mathrm{O}$, Hoster $\mathrm{E}$, Walewski J, et al. Addition of high-dose cytarabine to immunochemotherapy before autologous stem-cell transplantation in patients aged 65 years or younger with mantle cell lymphoma ( $\mathrm{MCL}$ Younger): a randomised, open-label, phase 3 trial of the European Mantle Cell Lymphoma Network. The Lancet.388(10044):565-575.

5. Dreyling M, Lenz G, Hoster E, et al. Early consolidation by myeloablative radiochemotherapy followed by autologous stem cell transplantation in first remission significantly prolongs progression-free survival in mantle-cell lymphoma: results of a prospective randomized trial of the European $\mathrm{MCL}$ Network. Blood. 2005;105(7):2677-2684.

6. Eskelund CW, Kolstad A, Jerkeman M, et al. 15-year follow-up of the Second Nordic Mantle Cell Lymphoma trial (MCL2): prolonged remissions without survival plateau. $\mathrm{Br} J$ Haematol. 2016;175(3):410-418.

7. Romaguera JE, Fayad L, Rodriguez MA, et al. High Rate of Durable Remissions After Treatment of Newly Diagnosed Aggressive Mantle-Cell Lymphoma With Rituximab Plus Hyper-CVAD Alternating With Rituximab Plus High-Dose Methotrexate and Cytarabine. J Clin Oncol. 2005;23(28):7013-7023.

8. Le Gouill S, Thieblemont C, Oberic L, et al. Rituximab after Autologous Stem-Cell Transplantation in Mantle-Cell Lymphoma. N Engl J Med. 2017;377(13):1250-1260.

9. Cheson BD, Fisher RI, Barrington SF, et al. Recommendations for Initial Evaluation, Staging, and Response Assessment of Hodgkin and Non-Hodgkin Lymphoma: The Lugano Classification. J Clin Oncol. 2014;32(27):3059-3067.

10. Cheson BD, Horning SJ, Coiffier B, et al. Report of an International Workshop to Standardize Response Criteria for Non-Hodgkin's Lymphomas. J Clin Oncol. 1999;17(4):1244-1244.

11. Chihara D, Cheah CY, Westin JR, et al. Rituximab plus hyper - CVAD alternating with MTX/Ara - C in patients with newly diagnosed mantle cell lymphoma: 15 - year follow - up of a phase II study from the MD Anderson Cancer Center. Br J Haematol. 2016;172(1):80-88.

12. Keane C, Gibbs S, Seymour JF, Mills A, Grimmett K, Van Kuilenberg R. The Hyper - CVAD chemotherapy regimen has an adverse long - term impact on the ability to mobilize peripheral blood stem cells, which can be readily circumvented by using the early cycles for mobilization. Hematol Oncol. 2006;24(3):159-163. 
13. Ritchie DS, Seymour JF, Grigg AP, et al. The hyper-CVAD-rituximab chemotherapy programme followed by high-dose busulfan, melphalan and autologous stem cell transplantation produces excellent event-free survival in patients with previously untreated mantle cell lymphoma. Ann Hematol. 2007;86(2):101-105.

14. Gerson JN, Handorf E, Villa D, et al. Survival Outcomes of Younger Patients With Mantle Cell Lymphoma Treated in the Rituximab Era. J Clin Oncol.0(0):JCO.18.00690.

15. Chen Y-B, Lane AA, Logan B, et al. Impact of Conditioning Regimen on Outcomes for Patients with Lymphoma Undergoing High-Dose Therapy with Autologous Hematopoietic Cell Transplantation. $B B$ \& MT. 2015;21(6):1046-1053.

\begin{tabular}{|l|l|l|l|l|l|l|}
\hline Regimens & Nordic & R- & R-CHOP & R- & Other $\sim$ & $P$-value \\
\hline
\end{tabular}

This article is protected by copyright. All rights reserved. 


\begin{tabular}{|c|c|c|c|c|c|c|}
\hline & MCL2* & $\begin{array}{c}\text { HCVAD/ } \\
\text { MA }\end{array}$ & & $\begin{array}{c}\text { CHOP/DHA } \\
\text { C }^{\#}\end{array}$ & & \\
\hline$N$ & $67(29 \%)$ & $60(26 \%)$ & $52(23 \%)$ & $19(8 \%)$ & $30(13 \%)$ & - \\
\hline $\begin{array}{l}\text { median age, } \\
\text { years (range) }\end{array}$ & $58(30-73)$ & $54(29-69)$ & $62(42-71)$ & $62(43-70)$ & $62(44-69)$ & $<0.001$ \\
\hline male & $51(76 \%)$ & $46(77 \%)$ & $38(73 \%)$ & $16(84 \%)$ & $25(83 \%)$ & 0.79 \\
\hline blastoid & $7(11 \%)$ & $1(3 \%)$ & $4(8 \%)$ & 0 & $2(8 \%)$ & 0.51 \\
\hline $\begin{array}{l}\text { Ki67 } \\
\text { - unknown } \\
-<\mathbf{3 0 \%} \\
-\geq \mathbf{3 0 \%}\end{array}$ & $\begin{array}{l}23(34 \%) \\
28(42 \%) \\
16(24 \%)\end{array}$ & $\begin{array}{l}33(55 \%) \\
15(25 \%) \\
12(20 \%)\end{array}$ & $\begin{array}{l}25(48 \%) \\
13(25 \%) \\
14(27 \%)\end{array}$ & $\begin{array}{l}7(36 \%) \\
6(32 \%) \\
6(32 \%)\end{array}$ & $\begin{array}{c}13(43 \%) \\
11(37 \%) \\
6(20 \%)\end{array}$ & 0.68 \\
\hline $\begin{array}{l}\text { stage } \\
\text { - unknown } \\
\text { - I/II } \\
\text { - III/IV }\end{array}$ & $\begin{array}{c}1(1 \%) \\
7(11 \%) \\
59(88 \%)\end{array}$ & $\begin{array}{c}1(2 \%) \\
5(8 \%) \\
54(90 \%)\end{array}$ & $\begin{array}{c}3(6 \%) \\
2(4 \%) \\
47(90 \%)\end{array}$ & $\begin{array}{c}0 \\
1(5 \%) \\
18(95 \%)\end{array}$ & $\begin{array}{c}0 \\
3(10 \%) \\
27(90 \%)\end{array}$ & 0.74 \\
\hline $\begin{array}{l}\text { B symptoms } \\
\text { - unknown } \\
\text { - yes } \\
\text { - no } \\
\end{array}$ & $\begin{array}{c}0 \\
22(33 \%) \\
45(67 \%) \\
\end{array}$ & $\begin{array}{c}2(3 \%) \\
21(35 \%) \\
37(62 \%)\end{array}$ & $\begin{array}{c}5(10 \%) \\
9(17 \%) \\
38(73 \%)\end{array}$ & $\begin{array}{c}2(10 \%) \\
7(37 \%) \\
10(53 \%)\end{array}$ & $\begin{array}{c}1(3 \%) \\
11(37 \%) \\
18(60 \%)\end{array}$ & 0.27 \\
\hline $\begin{array}{l}\text { performance } \\
\text { status } \\
\text { - unknown } \\
-0-1 \\
-\geq 2\end{array}$ & $\begin{array}{c}2(3 \%) \\
65(97 \%) \\
0\end{array}$ & $\begin{array}{c}1(2 \%) \\
57(95 \%) \\
2(3 \%)\end{array}$ & $\begin{array}{c}4(8 \%) \\
47(90 \%) \\
1(2 \%)\end{array}$ & $\begin{array}{c}0 \\
18(95 \%) \\
1(5 \%)\end{array}$ & $\begin{array}{c}0 \\
27(90 \%) \\
3(10 \%)\end{array}$ & 0.13 \\
\hline LDH elevated & $20(30 \%)$ & $25(42 \%)$ & $14(27 \%)$ & $8(42 \%)$ & $11(37 \%)$ & 0.64 \\
\hline $\begin{array}{l}\text { c-MIPI } \\
\text { - unknown } \\
\text { - low } \\
\text { - intermediate } \\
\text { - high } \\
\end{array}$ & $\begin{array}{l}16(24 \%) \\
19(28 \%) \\
19(28 \%) \\
13(20 \%)\end{array}$ & $\begin{array}{c}4(7 \%) \\
29(48 \%) \\
16(27 \%) \\
11(18 \%)\end{array}$ & $\begin{array}{l}8(16 \%) \\
11(21 \%) \\
22(42 \%) \\
11(21 \%)\end{array}$ & $\begin{array}{c}0 \\
5(26 \%) \\
6(32 \%) \\
8(42 \%)\end{array}$ & $\begin{array}{c}5(17 \%) \\
3(10 \%) \\
13(43 \%) \\
9(30 \%)\end{array}$ & 0.02 \\
\hline
\end{tabular}

Table 1. Baseline characteristics of patients according to type of induction treatment received.

Abbreviations: Nordic, rituximab (R), cyclophosphamide, vincristine, doxorubicin, prednisone (R-maxi$\mathrm{CHOP}$ ), alternating with high-dose cytarabine; R-Hyper-CVAD, rituximab, hyperfractionated cyclophosphamide, vincristine, doxorubicin and dexamethasone; R-CHOP; R-CHOP/DHAC, rituximab plus dexamethasone, doxorubicin, cytarabine and carboplatin; c-MIPI, combined MCL International Prognostic Index biologic index - with MIPI if Ki67 not available; LDH, lactate dehydrogenase.

* included 14 patients with R-CHOP with alternating cytarabine

\# included 2 patients with DHAP (dexamethasone, high dose cytarabine and cisplatin)

$\sim 5$ patients received R-CHOP/HCVAD, 5 received R-CHOP/ESHAP, 7 received R-CHOP/R-IVE, 2 received R-CVP, 1 received FCR, 1 received R-

CHOP/RIVAC/RESHAP, 1 received BR, 1 received BR+ ibrutinib/placebo, 1 received RCHOP/RDHAC/R-ICE, 1 received RCHOP/R-ICE, 1 received RCHP/cytarabine, 1 received chlorambucil/rituximab, 1 received RCEOP, 1 received RCHOP/BR/HCVAD, 1 received HCVAD/RDHAP. 


\begin{tabular}{|c|c|c|c|c|c|c|c|c|}
\hline \multirow{3}{*}{$\begin{array}{l}\text { Candidate } \\
\text { Factor }\end{array}$} & \multicolumn{4}{|c|}{ Univariate Analysis } & \multicolumn{4}{|c|}{ Multivariate Analysis } \\
\hline & \multicolumn{2}{|c|}{ PFS } & \multicolumn{2}{|l|}{ OS } & \multicolumn{2}{|c|}{ PFS } & \multicolumn{2}{|c|}{ OS } \\
\hline & $\begin{array}{c}\mathrm{HR} \\
(95 \% \mathrm{CI})\end{array}$ & $P$ & $\begin{array}{c}\mathrm{HR} \\
(95 \% \mathrm{CI})\end{array}$ & $P$ & $\begin{array}{c}\mathrm{HR} \\
(95 \% \mathrm{CI})\end{array}$ & $P$ & $\begin{array}{c}\mathrm{HR} \\
(95 \% \mathrm{CI})\end{array}$ & $P$ \\
\hline \multicolumn{9}{|l|}{ C-MIPI } \\
\hline Low & - & - & - & - & - & - & - & - \\
\hline Intermediate & $\begin{array}{c}1.38 \\
(0.84-2.25)\end{array}$ & 0.20 & $\begin{array}{c}1.26 \\
(0.63-2.50)\end{array}$ & 0.52 & - & - & - & - \\
\hline High & $\begin{array}{c}2.29 \\
(1.34-3.93)\end{array}$ & 0.003 & $\begin{array}{c}2.92 \\
(1.48-5.77)\end{array}$ & 0.002 & $\begin{array}{c}1.99 \\
(1.02-3.88)\end{array}$ & 0.044 & $\begin{array}{c}2.66 \\
(1.16-6.08)\end{array}$ & 0.021 \\
\hline Age $\geq 60$ & $\begin{array}{c}1.93 \\
(1.31-2.85)\end{array}$ & 0.001 & $\begin{array}{c}2.25 \\
(1.33-3.80)\end{array}$ & 0.003 & $\begin{array}{c}1.16 \\
(0.56-2.38)\end{array}$ & 0.69 & $\begin{array}{c}3.58 \\
(1.13- \\
11.28)\end{array}$ & $\mathbf{0 . 0 3 0}$ \\
\hline Male & $\begin{array}{c}0.71 \\
(0.43-1.15)\end{array}$ & 0.16 & $\begin{array}{c}0.67 \\
(0.35-1.29)\end{array}$ & 0.23 & - & - & - & - \\
\hline $\begin{array}{c}\text { Blastoid } \\
\text { histology }\end{array}$ & $\begin{array}{c}1.81 \\
(0.87-3.77) \\
\end{array}$ & 0.11 & $\begin{array}{c}2.75 \\
(1.15-6.56) \\
\end{array}$ & 0.023 & - & - & $\begin{array}{c}2.66 \\
(0.72-9.82) \\
\end{array}$ & 0.14 \\
\hline Ki67 $\geq 30 \%$ & $\begin{array}{c}2.15 \\
(1.26-3.67)\end{array}$ & 0.005 & $\begin{array}{c}3.02 \\
(1.41-6.49)\end{array}$ & 0.005 & $\begin{array}{c}2.83 \\
(1.38-5.83)\end{array}$ & 0.005 & $\begin{array}{c}2.16 \\
(0.73-6.41)\end{array}$ & 0.16 \\
\hline $\begin{array}{c}\text { Haemoglobin } \\
<120 \mathrm{~g} / \mathrm{l}\end{array}$ & $\begin{array}{c}1.21 \\
(0.74-1.99)\end{array}$ & 0.44 & $\begin{array}{c}0.87 \\
(0.43-1.76)\end{array}$ & 0.69 & - & - & - & - \\
\hline $\begin{array}{c}\text { White cell } \\
\text { count } \geq 13 \times \\
10^{9} / 1\end{array}$ & $\begin{array}{c}1.04 \\
(0.65-1.66)\end{array}$ & 0.88 & $\begin{array}{c}0.84 \\
(0.42-1.68)\end{array}$ & 0.63 & - & - & - & - \\
\hline Stage $\geq \mathbf{3}$ & $\begin{array}{c}4.02 \\
(1.27- \\
12.69)\end{array}$ & 0.018 & $*$ & - & $\begin{array}{c}1.41 \\
(0.30-6.71)\end{array}$ & 0.66 & * & - \\
\hline B symptoms & $\begin{array}{c}1.57 \\
(1.04-2.38)\end{array}$ & 0.032 & $\begin{array}{c}1.75 \\
(1.01-3.02)\end{array}$ & 0.043 & $\begin{array}{c}2.73 \\
(1.30-5.77)\end{array}$ & 0.008 & $\begin{array}{c}3.63 \\
(1.30- \\
10.11)\end{array}$ & 0.014 \\
\hline$E C O G \geq 1$ & $\begin{array}{c}1.66 \\
(1.11-2.50)\end{array}$ & 0.015 & $\begin{array}{c}2.05 \\
(1.20-3.51)\end{array}$ & 0.009 & $\begin{array}{c}1.10 \\
(0.48-2.51)\end{array}$ & 0.82 & $\begin{array}{c}1.64 \\
(0.59-4.59)\end{array}$ & 0.35 \\
\hline Elevated LDH & $\begin{array}{c}1.37 \\
(0.90-2.10)\end{array}$ & 0.15 & $\begin{array}{c}2.09 \\
(1.21-3.60)\end{array}$ & 0.008 & - & - & $\begin{array}{c}1.35 \\
(0.50-3.69)\end{array}$ & 0.55 \\
\hline $\begin{array}{c}\text { Bone marrow } \\
\text { involvement }\end{array}$ & $\begin{array}{c}2.07 \\
(0.94-4.54)\end{array}$ & 0.07 & $\begin{array}{c}3.16 \\
(0.76- \\
13.15)\end{array}$ & 0.11 & $\begin{array}{c}0.95 \\
(0.34-2.66)\end{array}$ & 0.92 & - & - \\
\hline $\begin{array}{l}\text { Type of } \\
\text { Induction } \\
\text { regimen }\end{array}$ & & & & & & & & \\
\hline Nordic MCL2 & - & - & - & - & - & - & - & - \\
\hline
\end{tabular}

This article is protected by copyright. All rights reserved. 


\begin{tabular}{|c|c|c|c|c|c|c|c|c|}
\hline $\begin{array}{c}\text { R- } \\
\text { HCVAD/MA } \\
\end{array}$ & $\begin{array}{c}0.82 \\
(0.47-1.45) \\
\end{array}$ & 0.49 & $\begin{array}{c}0.92 \\
(0.43-1.95) \\
\end{array}$ & 0.82 & $\begin{array}{c}0.86 \\
(0.42-1.73) \\
\end{array}$ & 0.67 & $\begin{array}{c}1.25 \\
(0.50-3.12) \\
\end{array}$ & 0.63 \\
\hline R-CHOP & $\begin{array}{c}1.22 \\
(0.69-2.15)\end{array}$ & 0.50 & $\begin{array}{c}0.71 \\
(0.31-1.66)\end{array}$ & 0.43 & $\begin{array}{c}1.14(0.57- \\
2.30)\end{array}$ & 0.71 & $\begin{array}{c}0.65 \\
(0.26-1.61)\end{array}$ & 0.35 \\
\hline $\begin{array}{c}\text { R- } \\
\text { CHOP/DHAC }\end{array}$ & $\begin{array}{c}1.31 \\
(0.53-3.25)\end{array}$ & 0.56 & $\begin{array}{c}1.27 \\
(0.35-4.57)\end{array}$ & 0.72 & $*$ & - & $\begin{array}{c}0.70 \\
(0.15-3.27) \\
\end{array}$ & 0.65 \\
\hline Other & $\begin{array}{c}1.27 \\
(0.68-2.38) \\
\end{array}$ & 0.46 & $\begin{array}{c}1.26 \\
(0.54-2.94) \\
\end{array}$ & 0.60 & $\begin{array}{c}1.31 \\
(0.61-2.80)\end{array}$ & 0.49 & $\begin{array}{c}1.08 \\
(0.42-2.79) \\
\end{array}$ & 0.87 \\
\hline $\begin{array}{l}\text { Cytarabine } \\
\text { containing } \\
\text { regimen }\end{array}$ & $\begin{array}{c}0.77 \\
(0.51-1.14)\end{array}$ & 0.19 & $\begin{array}{c}1.16 \\
(0.66-2.05)\end{array}$ & 0.61 & $\begin{array}{c}0.84 \\
(0.48-1.46)\end{array}$ & 0.53 & $\begin{array}{c}1.41 \\
(0.70-2.85)\end{array}$ & 0.34 \\
\hline \multicolumn{9}{|l|}{$\begin{array}{c}\text { Type of } \\
\text { myeloablative }\end{array}$} \\
\hline Bu/Mel & - & - & - & - & - & - & - & - \\
\hline BEAM & $\begin{array}{c}2.02 \\
(1.11-3.68)\end{array}$ & 0.021 & $\begin{array}{c}1.10 \\
(0.53-2.28)\end{array}$ & 0.79 & $\begin{array}{c}1.61 \\
(0.48-5.38)\end{array}$ & 0.44 & - & - \\
\hline Other & $\begin{array}{c}1.08 \\
(0.35-3.32)\end{array}$ & 0.89 & $\begin{array}{c}0.41 \\
(0.05-3.18)\end{array}$ & 0.39 & - & - & - & - \\
\hline
\end{tabular}

Table 2: Prognostic factors for progression free and overall survival by univariate and multivariate analysis. Bold denotes $P<0.05$.

* No events in this group, $95 \% \mathrm{CI}$ undefined.

Abbreviations: C-MIPI (combined MCL International Prognostic Index biologic index, with MIPI only if Ki67 was not available); ECOG, Eastern Cooperative Oncology Group; LDH, lactate dehydrogenase;

Nordic, rituximab (R), cyclophosphamide, vincristine, doxorubicin, prednisone (R-maxi-CHOP), alternating with high-dose cytarabine; R-Hyper-CVAD, rituximab, hyperfractionated cyclophosphamide, vincristine, doxorubicin and dexamethasone; R-CHOP; R-CHOP/DHAC, rituximab plus dexamethasone, doxorubicin, cytarabine and carboplatin; BuMel, busulfan and melphalan; BEAM, carmustine, etoposide, cytarabine, melphalan. 


\begin{tabular}{|c|c|c|c|c|c|c|}
\hline Regimens & $\begin{array}{l}\text { Nordic } \\
\text { MCL2* }\end{array}$ & $\begin{array}{c}\text { R-Hyper- } \\
\text { CVAD/M } \\
\text { A } \\
\end{array}$ & R-CHOP & $\begin{array}{c}\text { R- } \\
\text { CHOP/DHA } \\
C^{\#} \\
\end{array}$ & Other & $P$-value \\
\hline $\begin{array}{l}\text { median follow } \\
\text { up, years } \\
\text { (range) }\end{array}$ & $\begin{array}{l}2.5(0.6- \\
15.0)\end{array}$ & $\begin{array}{c}6.7(1.7- \\
14.7)\end{array}$ & $\begin{array}{c}5.5(0.4- \\
12.2)\end{array}$ & $2.8(0.8-5.8)$ & $\begin{array}{c}6.7(0.5- \\
13.9)\end{array}$ & - \\
\hline $\begin{array}{l}\text { myeloablative } \\
\text { therapy }\end{array}$ & $57(88 \%)$ & $43(72 \%)$ & $37(76 \%)$ & $14(78 \%)$ & $21(78 \%)$ & 0.23 \\
\hline $\begin{array}{l}\text { conditioning } \\
\text { regimen } \\
\text { - BuMel } \\
\text { - BEAM } \\
\text { - other }\end{array}$ & $\begin{array}{c}2(4 \%) \\
49(86 \%) \\
6(11 \%)\end{array}$ & $\begin{array}{c}29(67 \%) \\
13(31 \%) \\
1(2 \%)\end{array}$ & $\begin{array}{c}4(12 \%) \\
29(79 \%) \\
3(9 \%)\end{array}$ & $\begin{array}{c}0 \\
3(21 \%) \\
11(79 \%) \text { ? }\end{array}$ & $\begin{array}{c}4(17 \%) \\
17(81 \%) \\
0\end{array}$ & - \\
\hline $\begin{array}{l}\text { maintenance } \\
\text { rituximab }\end{array}$ & $11(20 \%)$ & $7(17 \%)$ & $9(26 \%)$ & $1(7 \%)$ & $1(5 \%)$ & 0.43 \\
\hline ORR & $63(94 \%)$ & $60(100 \%)$ & $46(88 \%)$ & $18(95 \%)$ & $26(87 \%)$ & 0.11 \\
\hline $\begin{array}{l}\text { 4-year PFS } \\
(95 \% \text { CI })\end{array}$ & $\begin{array}{c}65 \% \\
(48-78) \\
\end{array}$ & $\begin{array}{c}65 \% \\
(51-76) \\
\end{array}$ & $\begin{array}{c}51 \% \\
(35-65) \\
\end{array}$ & $\begin{array}{c}69 \% \\
(35-88) \\
\end{array}$ & $\begin{array}{c}63 \% \\
(42-78) \\
\end{array}$ & 0.48 \\
\hline $\begin{array}{l}\text { 4-year OS } \\
(95 \% \text { CI) }\end{array}$ & $\begin{array}{c}84 \% \\
(70-92)\end{array}$ & $\begin{array}{c}84 \% \\
(72-92)\end{array}$ & $\begin{array}{c}88 \% \\
(74-95)\end{array}$ & $\begin{array}{c}80 \% \\
(49-93)\end{array}$ & $\begin{array}{c}74 \% \\
(53-87)\end{array}$ & 0.71 \\
\hline
\end{tabular}

Table 3. Treatment received and outcomes of patients according to type of induction treatment received.

Abbreviations: Nordic, rituximab (R), cyclophosphamide, vincristine, doxorubicin, prednisone (R-maxi$\mathrm{CHOP}$ ), alternating with high-dose cytarabine; R-Hyper-CVAD, rituximab, hyperfractionated cyclophosphamide, vincristine, doxorubicin and dexamethasone; R-CHOP; R-CHOP/DHAC, rituximab plus dexamethasone, doxorubicin, cytarabine and carboplatin; BuMel, busulfan and melphalan; BEAM, carmustine, etoposide, cytarabine, melphalan; ORR, overall response rate, PFS, progression free survival; OS, overall survival.

* included 10 patients with R-CHOP with alternating cytarabine

\# included 2 patients with DHAP (dexamethasone, high dose cytarabine and cisplatin) 
[] Four underwent Cyclophosphamide and total body irradiation (TBI) conditioning, two underwent cyclophosphamide, TBI and melphalan conditioning and five underwent LACE (lomustine, etoposide, cytarabine and cyclophosphamide) conditioning.

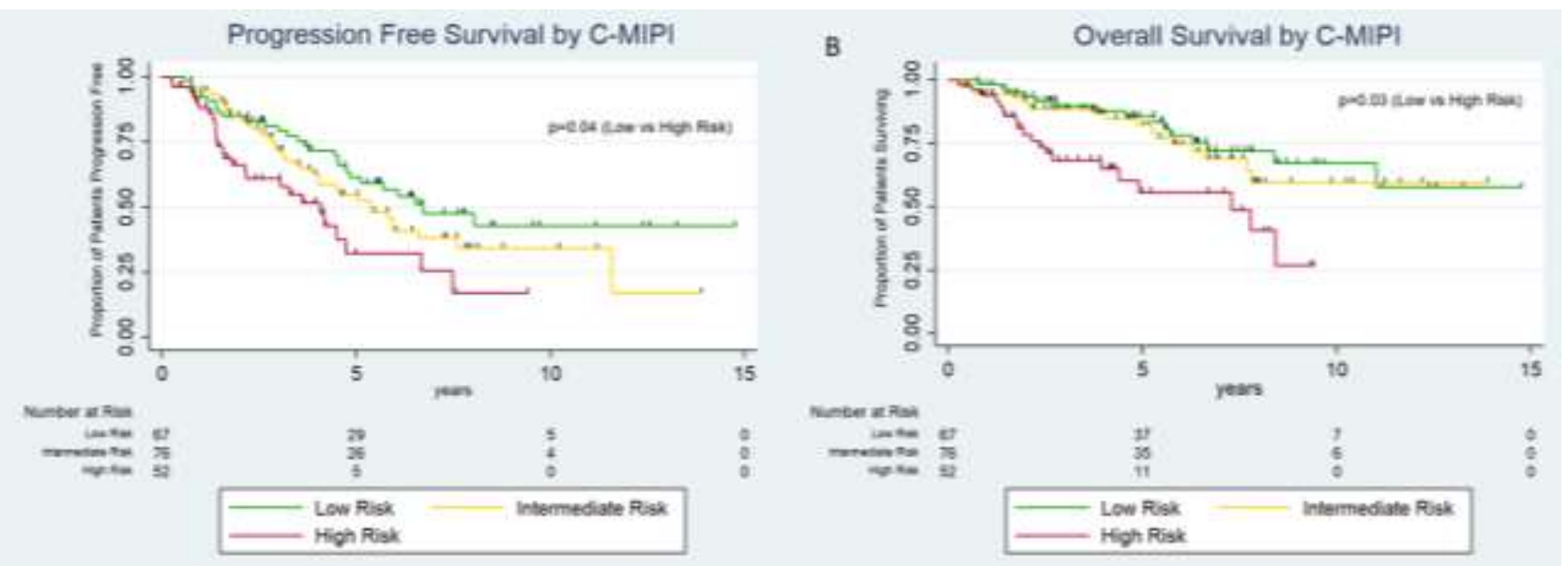

Figure 1. (A) Progression free survival by C-MIPI stratified risk groups. (B) Overall survival by C-MIPI stratified risk groups.

Abbreviations: C-MIPI (combined MCL International Prognostic Index biologic index, with MIPI only if Ki67 was not available). 

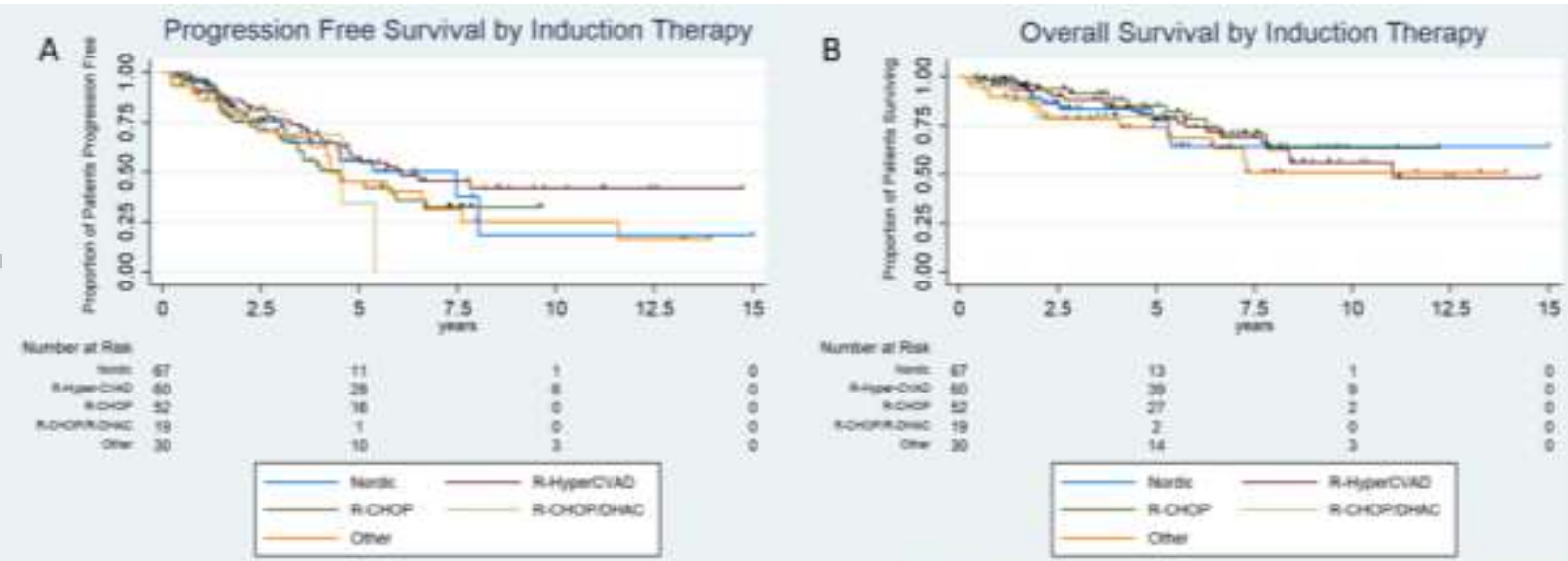

C

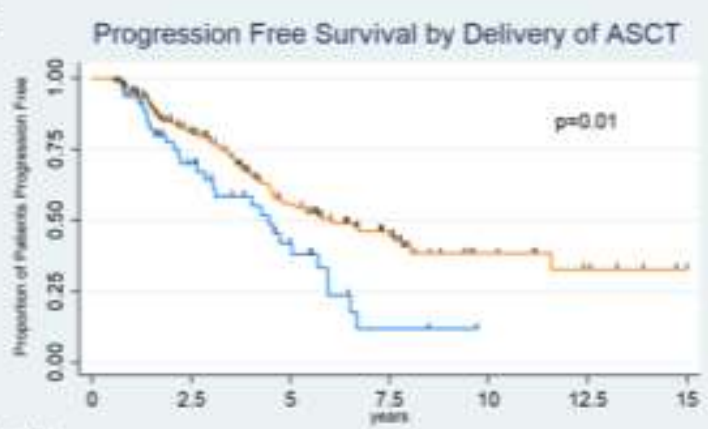

D Progression Free Survival by Conditioning Regimen

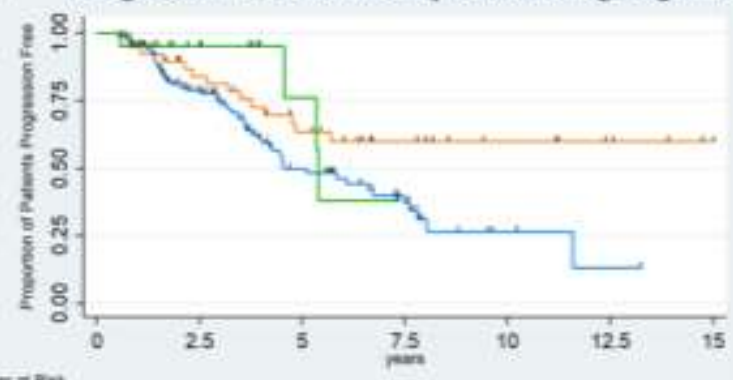

nenters in

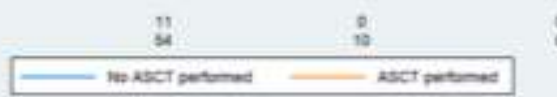

플

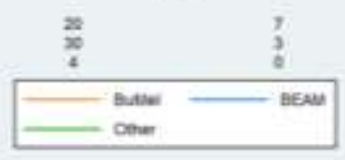

Figure 2. (A) Progression free survival by induction therapy. (B) Overall survival by induction therapy. (C) Progression free survival by delivery of autologous stem-cell transplant (ASCT). (D) Progression free survival by type of conditioning regimen.

Abbreviations: Nordic, rituximab (R), cyclophosphamide, vincristine, doxorubicin, prednisone (R-maxiCHOP), alternating with high-dose cytarabine; R-Hyper-CVAD, rituximab, hyperfractionated cyclophosphamide, vincristine, doxorubicin and dexamethasone; R-CHOP; R-CHOP/DHAC, rituximab plus dexamethasone, doxorubicin, cytarabine and carboplatin; BuMel, busulfan and melphalan; BEAM, carmustine, etoposide, cytarabine, melphalan. 


\section{University Library}

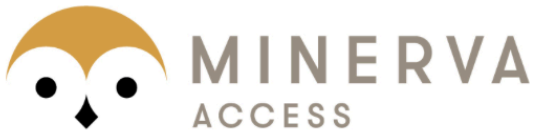

A gateway to Melbourne's research publications

Minerva Access is the Institutional Repository of The University of Melbourne

\section{Author/s:}

Ng, ZY;Bishton, M;Ritchie, D;Campbell, R;Gilbertson, M;Hill, K;Ratnasingam, S;Schwarer, A;Manos, K;Shorten, S;Ng, M;Nelson, N;Xin, L;De Mel Widanalage, S;Sunny, T;Purtill, D;Poon, M;Johnston, A;Cochrane, T;Lee, H-P;Hapgood, G;Tam, C;Opat, S;Hawkes, E;Seymour, J;Cheah, CY

Title:

A multicenter retrospective comparison of induction chemoimmunotherapy regimens on outcomes in transplant-eligible patients with previously untreated mantle cell lymphoma

Date:

2019-08-01

\section{Citation:}

Ng, Z. Y., Bishton, M., Ritchie, D., Campbell, R., Gilbertson, M., Hill, K., Ratnasingam, S., Schwarer, A., Manos, K., Shorten, S., Ng, M., Nelson, N., Xin, L., De Mel Widanalage, S., Sunny, T., Purtill, D., Poon, M., Johnston, A., Cochrane, T. ,... Cheah, C. Y. (2019). A multicenter retrospective comparison of induction chemoimmunotherapy regimens on outcomes in transplant-eligible patients with previously untreated mantle cell lymphoma. HEMATOLOGICAL ONCOLOGY, 37 (3), pp.253-260. https://doi.org/10.1002/hon.2618.

Persistent Link:

http://hdl.handle.net/11343/285888 